\title{
A Comparative Study of Recycling of Used Engine Oil Using Extraction by Composite Solvent, Single Solvent, and Acid Treatment Methods
}

\author{
Rashid Abro, ${ }^{1}$ Xiaochun Chen, ${ }^{1}$ Khanji Harijan, ${ }^{2}$ \\ Zulifqar A. Dhakan, ${ }^{3}$ and Muhammad Ammar ${ }^{1}$ \\ ${ }^{1}$ College of Chemical Engineering, Beijing University of Chemical Technology, Beijing 100029, China \\ ${ }^{2}$ Department of Mechanical Engineering, Mehran University of Engineering and Technology, Jamshoro 76062, Pakistan \\ ${ }^{3}$ Pakistan Council of Scientific and Industrial Research, Karachi 75280, Pakistan
}

Correspondence should be addressed to Xiaochun Chen; chenxc@mail.buct.edu.cn

Received 28 May 2013; Accepted 19 June 2013

Academic Editors: A. M. Seayad and F. Secundo

Copyright (C) 2013 Rashid Abro et al. This is an open access article distributed under the Creative Commons Attribution License, which permits unrestricted use, distribution, and reproduction in any medium, provided the original work is properly cited.

\begin{abstract}
Engine oils are made from crude oil and its derivatives by mixing of certain other chemicals (additives) for improving their certain properties. Lubricating oil is used to lubricate moving parts of engine, reducing friction, protecting against wear, and removing contaminants from the engine, act as a cleaning agent, and act as an anticorrosion and cooling agent. This research effort focuses on comparative study of re-refined engine oils by extraction of composite solvent, single solvent, and acid treatment methods. Composite solvent was made up of butanol-propane and butanone; propane was used as single solvent. Different properties of refined oil and waste oil were analyzed, such as cloud and pour point, flash point, specific gravity, ash content, viscosity, moisture ratio and acid value. On the basis of experimental work, it was found that the iron contamination decreased from $50 \mathrm{ppm}$ to $13 \mathrm{ppm}$ for composite solvent; for propane solvent it decreased up to $30 \mathrm{ppm}$ and $15 \mathrm{ppm}$ for acid treatment. Results from the flash point, pour point, viscosity, specific gravity, and ash percentage were improved at different degrees, but the best results were seen by using the composite solvent with having drawback of expensiveness.
\end{abstract}

\section{Introduction}

Large quantity of used engine oils from different sources is disposed as a harmful waste into the environment in Pakistan [1], and disposal of used oil in Arabian Sea, rivers, and lakes in the environment creates series of problems; their disposals in water bodies not only contaminate water but are also harmful to fresh water and marine life. Roughly one gallon of used engine oil would contaminate one million gallon of water including fauna and flora [2].

Lubricant oil is used in automobile engines to lubricate moving parts of engine, reducing friction, protect, against wear, and removing contaminants from the engine, act as a cleaning agent, and act as an anticorrosive and cooling agent. It picks up a number of impurities and additional components from engine wear. These components include metal particles (iron, steel, copper, lead, zinc, etc.) and other compounds of barium, sulfur, water, dirt, burnt carbon, and ash, most of them are highly toxic in nature; therefore these contaminants must be separated in order to reuse the engine oil.

So many additives are used in engine oil for preventing unwanted properties. The main additives for engine oil are oxidation inhibitor, pour point depressants, colorings agent, anticorrosion agents, and so forth. Recycling of spent lubricating oils mostly depends on the nature of the oil base stock and on the nature and amount of contaminants in the lubricant resulting from operations. The contaminants are introduced both from the surrounding air and from the engine [3-7].

\section{Properties of Engine Oil}

(i) Viscosity. Viscosity analysis shows the presence of different type of contamination in used engine oil. The products of 


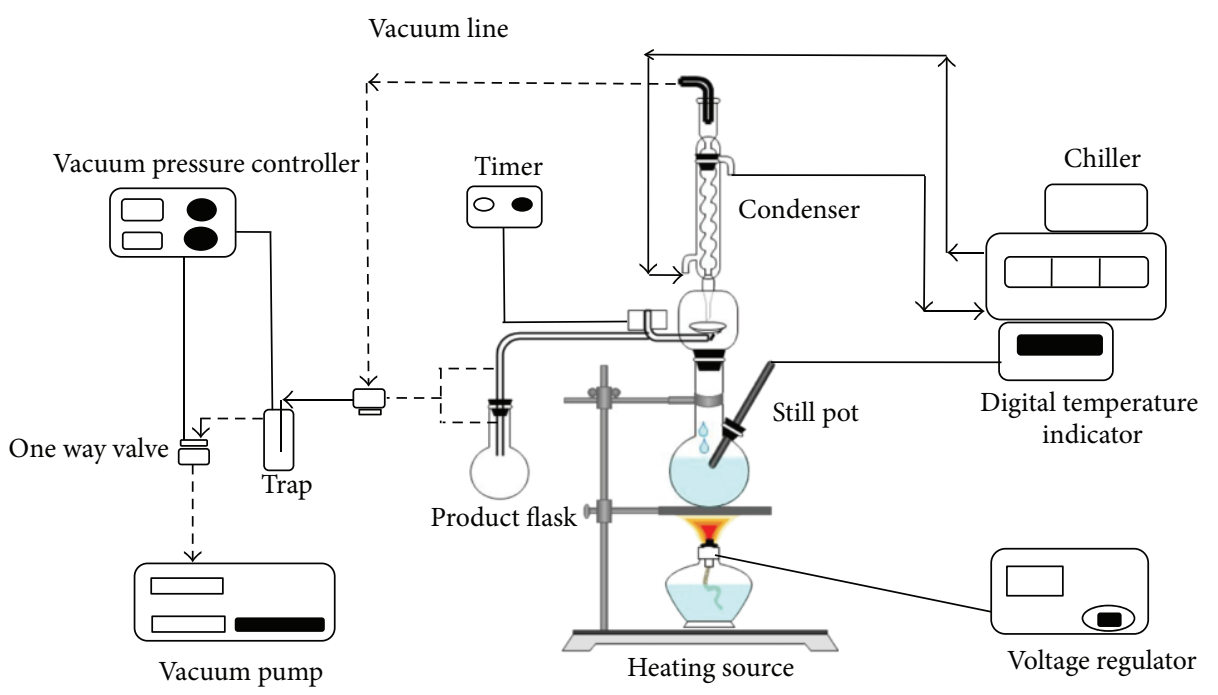

Figure 1: Vacuum distillation of water and light fuels.

oxidation and polymerization (these products can be both dissolved and suspended) in the oil cause the increase the viscosity of used engine oil, in while a decrease in the viscosity of engine oil shows the fuel contamination [8].

(ii) Pour Point. Pour point may be defined as the lowest temperature at which the oil will stop to flow. Lubricating oil having low pour pint shows its good quality.

(iii) Flash Point. Flash point is the lowest temperature at which the vapors in air will burn momentarily if ignited by flame or spark. A decrease in flash point indicates contamination by dilution of lubricating oils with unburned fuel. Increasing of flash point indicates evaporation of the light components from the lubricating oil [9].

(iv) Acidity or Neutralization Number. This is also one of the important chemical properties. It shows the amount of alkali required to neutralize unit mass of the oil. Normally it increases due to oxidation of lubricating oil.

(v) Ash Content. When the lubricating oil is completely burned, the remaining solid is called ash and it shows the oil purity.

(vi) Carbon or Coking Test. This evaluates the solid residue obtained when the oil is heated to complete vaporization and it refers to the amount of deposit formed.

(vii) Water Content. This test is done by distillation and indicates the amount of water emulsified in the oil.

(viii) Fuel Contaminants. It is an amount of fuel (diesel, petrol, etc.) diluting in the lubricating oil during automotive operation [10].

(xi) Cloud and Pour Points. Cloud point is the temperature at which paraffinic wax and other oils are cooled under a given condition. Pour point is not a measure of the temperature at which the oil ceases to flow under service conditions of a specific system. It is very important to users of lubricants in low temperature environment.

\section{Materials and Method}

3.1. Collection of Used Engine Oil. Samples of used engine oil of heavy vehicles, light vehicles, and blended oil were collected from the transport office of PCSIR-KLC Karachi.

3.2. Experimental Work. Studies have been carried out utilizing the two different approaches, extraction and acid treatment, respectively, after the dehydration and removal of light fuels by vacuum distillation of waste engine oil at 2-8 m Bar. The apparatus of vacuum distillation was set as shown in Figure 1.

The first approach considered the function of solvent extraction that was divided into two subfunctions; single solvent extraction and multicomponent solvent extraction butanol 38\%, propanol 37\%, and butanone 25\% were used to form a composite solvent then that was mixed with oil in the ratio (oil:composite solvent) of $1: 2,1: 3$, and $1: 4$ in that order. The obtained sludge was separated after 12 hours. Solvents were recovered by vacuum distillation and remaining materials as required products completely analyzed. The second approach was consisting of mixing the raw material and sulfuric acid with the ratio of $10: 1$ (oil : acid) at $60^{\circ} \mathrm{C}$. That acidified material was neutralized with caustic soda of $20 \%$ solution and filtered to remove precipitate in the result of neutralization. The filtration gave clear liquid containing required product that was analyzed.

In order to collect data of products with respect to two different methods of chemical process engineering, samples were sent to PCSIR laboratories Complex Karachi for the validation and verification of results. 


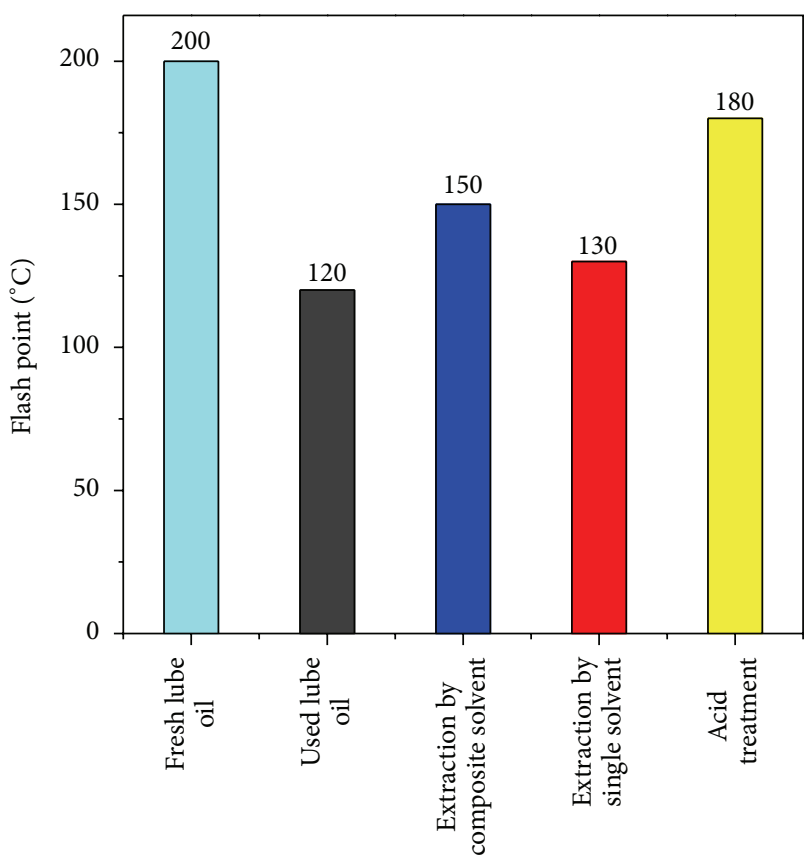

Figure 2: Effect of refining on flash point.

\section{Results and Discussion}

4.1. Flash Point. The flash points of samples were analyzed by open cup flash point apparatus by ASTM D97. A beaker containing $10 \mathrm{~mL}$ of sample was placed on Bunsen Burner, which was fitted with thermometer. A flame source was brought at intervals to determine the temperature at which a flash appears on the surface of the sample while the lube oil in the beaker was heated.

The flash point of fresh lube oil is $200^{\circ} \mathrm{C}$, for used engine oil flash point is $120^{\circ} \mathrm{C}$, in extraction by composite solvent treatment method flash point is $150^{\circ} \mathrm{C}$, extraction by single solvent treatment $130^{\circ} \mathrm{C}$, and acid treatment method flash point is $180^{\circ} \mathrm{C}$ as shown in Figure 2 . Lowering the value of flash point of used engine oil is because of presence of light fuels [9]. However, flash point of extraction by composite solvent and acid treatment is suitable.

4.2. Specific Gravity. Specific gravity of treated oil samples was analyzed by digital hydrometer of Thermo-Hygro. Specific gravity of fresh engine oil was 0.90 , while the specific gravity of used engine oil was 0.93 . the result of the specific gravity for the composite solvent extraction treatment is 0.88 , the specific gravity of single solvent single solvent extraction treatment is 0.858 , and specific gravity of acid treatment is 0.909 as shown in Figure 3. We found that the value of specific gravity of used engine oil is more for recycled oil by different methods. It could be lower or higher than fresh engine oil depending on the nature and type of contaminations [11].

4.3. Viscosity. Kinetic viscosity of used engine oil can be increased due to oxidation or contamination, while it may also be decreased due to dilution with light fuels (diesel or

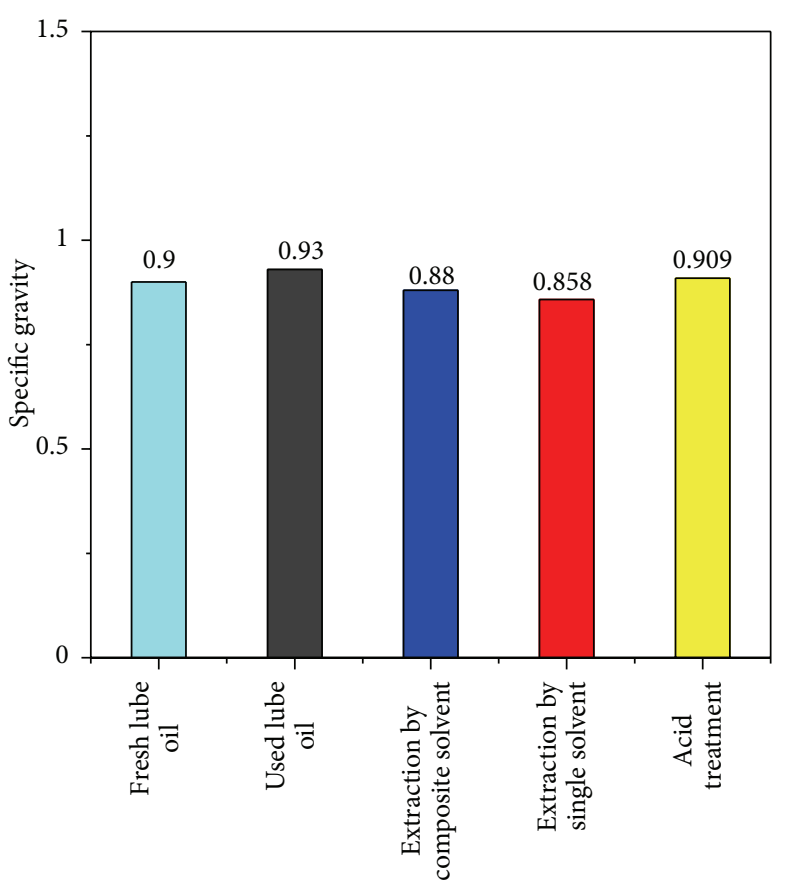

FIGURE 3: Effect of refining on specific gravity.

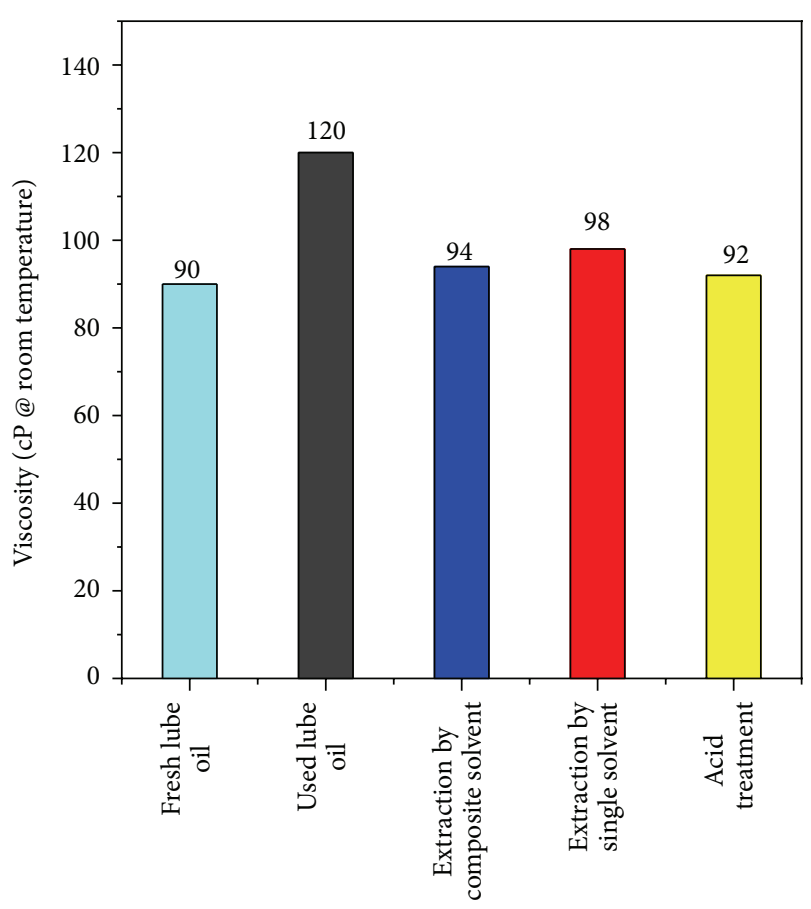

FIGURE 4: Effect of refining on viscosity.

petrol) [8]. Viscosity of fresh lube oil is $90 \mathrm{cP}$, used engine oil $120 \mathrm{cP}$, which shows presence of contaminations in used engine oil, where the viscosity values of refined engine oils by composite solvent method, single solvent method, and acid treatment method are $94 \mathrm{cp}, 98 \mathrm{cP}$, and $92 \mathrm{cP}$, respectively. Figure 4 shows that the used oil has high viscosity due to 


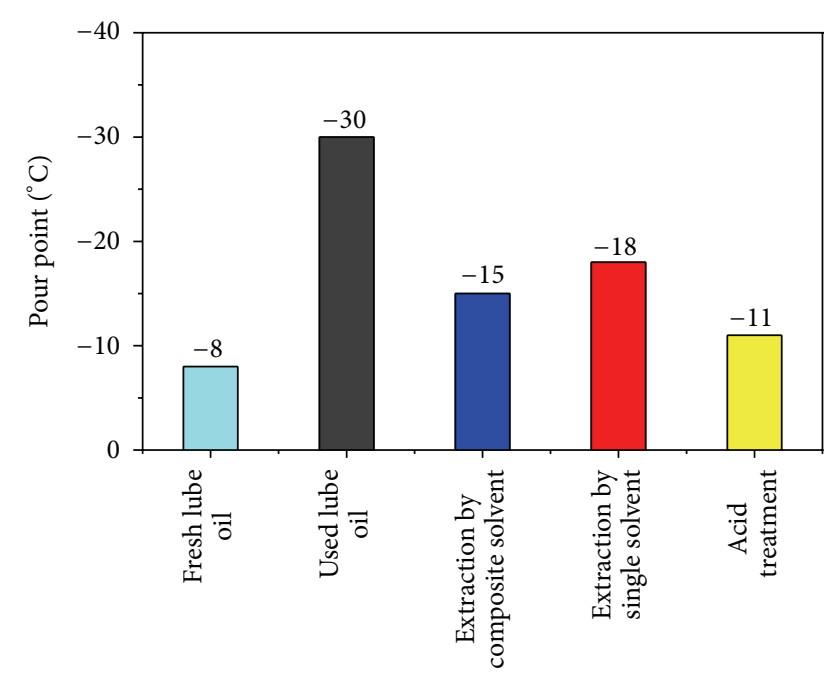

FIGURE 5: Effect of refining on pour point.

contaminations. Acid treatment method has an advantage over others.

4.4. Pour Point. Pour points of samples were analyzed by pour point apparatus by ASTM D97 in which $20 \mathrm{~mL}$ of samples of oil were introduced into a test tube, and then the samples were highly cooled at specific rate. The temperature at which certain hydrocarbons (Paraffin) began to convert into crystalline form called cloud point. On further cooling the oil samples stopped to flow, and that temperature was called the pour point of that oil. By this way cloud point and pour point of used and re-refined engine oil were analyzed.

Pour point of lube oil may be decreased and increased, depending on the nature of lube oil method of refining [12]. The result chart in Figure 5 shows that the pour point of fresh oil is $-8^{\circ} \mathrm{C}$ and used engine oil is $-30^{\circ} \mathrm{C}$. This decrease in pour point is because of degradations of additives, which were present in fresh oil as pour point depressants. Pour Point values of refined engine oils by composite solvent, single solvent, and acid treatment are $-15^{\circ} \mathrm{C},-18^{\circ} \mathrm{C}$, and $-11^{\circ} \mathrm{C}$, respectively. These results show that the two methods (i.e., acid treatment and extraction by composite solvent) are comparatively better than single solvent extraction method.

4.5. Ash Percentage. From experiment result it was found that the percentage of ash in fresh oil is $0.01 \%$, percentage of ash in used engine oil is $2.02 \%$, percentage of refined oil by Composite extraction is $0.09 \%$, in single solvent treatment $0.15 \%$ ash was found, and acid treatment method gave $0.04 \%$ ash in refined oil as shown in Figure 6. The acid treatment method and extraction by composite solvents has an advantage over single solvent extraction treatment.

4.6. Iron Contents. Iron contamination of oil samples was analyzed by Atomic Absorption Spectrometer.

Also, $10 \mathrm{~mL}$ of samples of oil in Pt-dish and 3-4 mL of concentrate $\mathrm{H}_{2} \mathrm{SO}_{4}$ drop wise were added in it and heated

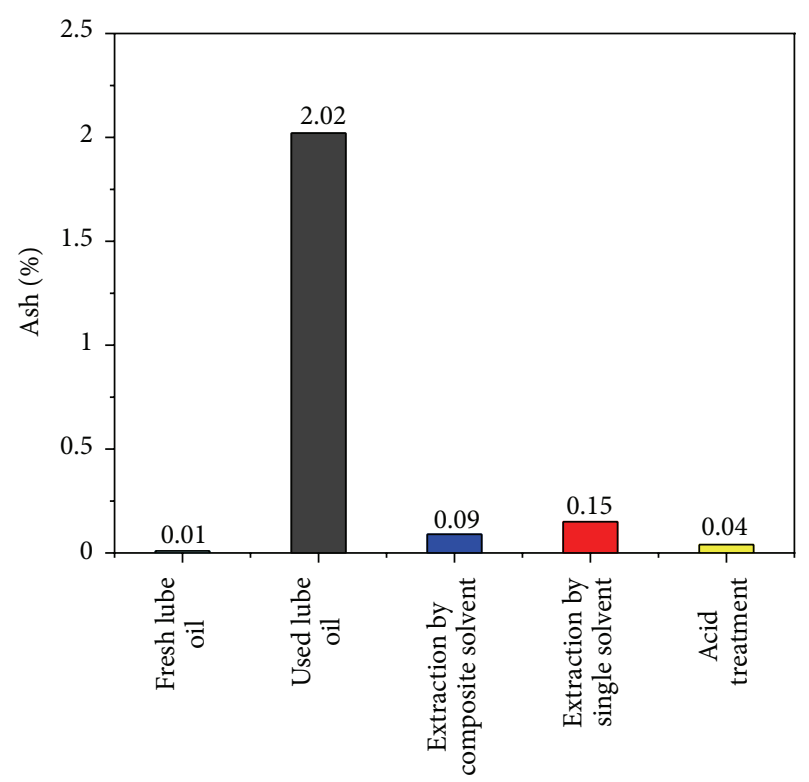

FIGURE 6: Effect of refining on ash percentage.

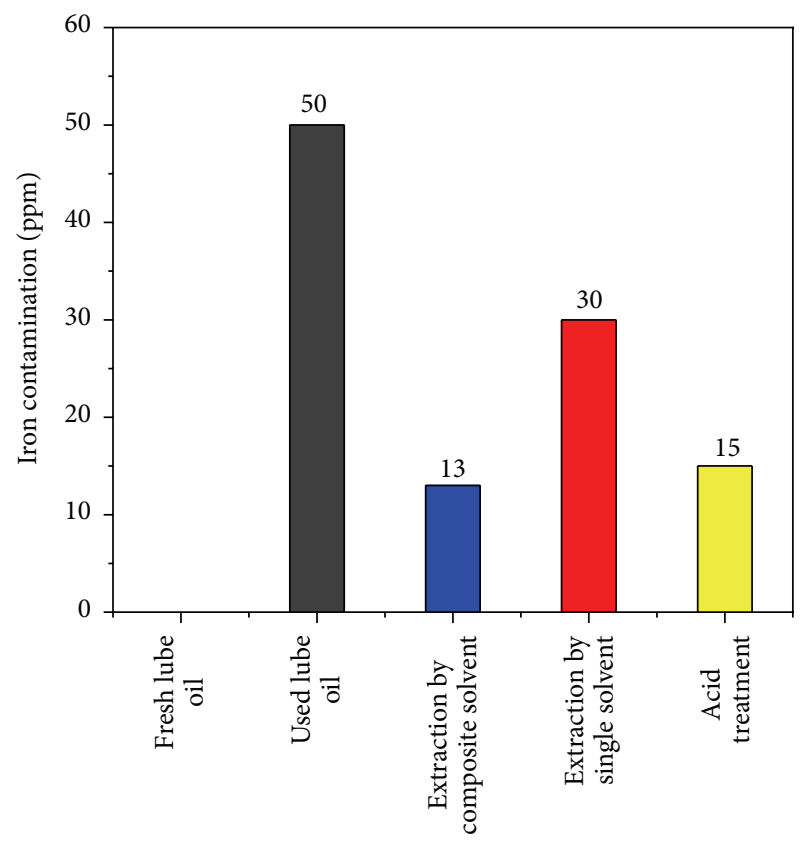

FIGURE 7: Effect of refining on iron contamination.

it over low flame till dryness. Drying took 28 hours. After drying the dish was placed in a furnace at $700^{\circ} \mathrm{C}$, and after that $5-10 \mathrm{~mL}$ of HCL were added in it and made the solution of sample in D-water.

Block of any engine is mostly made of iron, aluminum, and lead, and during the combustion in the engine chamber of any fuel, the tinny parts of these metals are found in used engine oil in parts per million. The wear of these metals in an engine chamber is because of corrosion caused due to water and aided by dilution of fuel and it is because of bad piston rings [10]. Figure 7 shows the iron contamination reduced 
by composite solvent from 50 to $13 \mathrm{ppm}$, by single solvent $30 \mathrm{ppm}$, and by acid treatment it is reduced up to $15 \mathrm{ppm}$.

\section{Conclusions}

On the basis of experimental work, it is found that all methods effectively removed contaminants from used lubricating base oil and returned the oil to a quality essentially equivalent to oils produced by fresh lube oil stocks. Extraction by composite solvent is one of the best methods of recycling but having drawback of expensiveness of solvents used in recycling. After extraction by composite solvent method, on the basis of experimental work, acid treatment method is the second best method. Acid treatment method is much cheaper than extraction by composite solvent method. The main drawback of acid treatment is high acid value which creates series of environmental problems.

\section{References}

[1] M. Shakirullah, I. Ahmad, M. Saeed et al., "Environmentally friendly recovery and characterization of oil from used engine lubricants," Journal of the Chinese Chemical Society, vol. 53, no. 2, pp. 335-342, 2006.

[2] J. L. A. Filho, L. G. M. Moura, and A. C. S. Ramos, "Liquidliquid extraction and adsorption on solid surfaces applied to used lubricant oils recovery," Brazilian Journal of Chemical Engineering, vol. 27, no. 4, pp. 687-697, 2010.

[3] F. O. Cotton, "Waste lubricating oil: an annotated review," REVISION DEB3001439 of Annotated Review 1997 BETC/IC 79/4, CORP; Source- Department of Energy, Bartlesville, Okla, USA, 1997.

[4] A. Hamad, E. Al-Zubaidy, and M. E. Fayed, "Used lubricating oil recycling using hydrocarbon solvents," Journal of Environmental Management, vol. 74, no. 2, pp. 153-159, 2005.

[5] M. k. Jha, "Re-refining of used lube oils: an intelligent and ecofriendly option," Indian Chemical Engineering, vol. 473, pp. 209211, 2005.

[6] R. R. F. Kinghorn, An Introduction to the Physics and Chemistry of Petroleum, John Wiley \& Sons, New York, NY, USA, 1983.

[7] J. D. Udonne, "A comparative study of recycling of used lubrication Oils using Distillation, acid and activated charcoal with clay methods," Journal of Petroleum and Gas Engineering, vol. 2, no. 2, pp. 12-19, 2011.

[8] M. Scapin, "Recycling of used lubricating oils by Ionizing, linking hub," Elservier.com/retrieval/pii/30969806X0700182X, 2007.

[9] J. Rincon, "Regeneration of used lubricant oil by polar solvent extraction," Industrial \& Engineering Chemistry Research, vol. 44, no. 12, pp. 4373-4379, 2005.

[10] S. Boyde, "Green Lubricants. Environmental benefits and impacts of lubrication," Green Chemistry, vol. 4, no. 4, pp. 293$307,2002$.

[11] Chevron Lubricating oil FM ISO 100.

[12] F. Awaja and D. Pavel, "Design aspects of used lubricating oil redefining," Books.google.com.ng/books?isbn=044452228X, p. 114,2006 

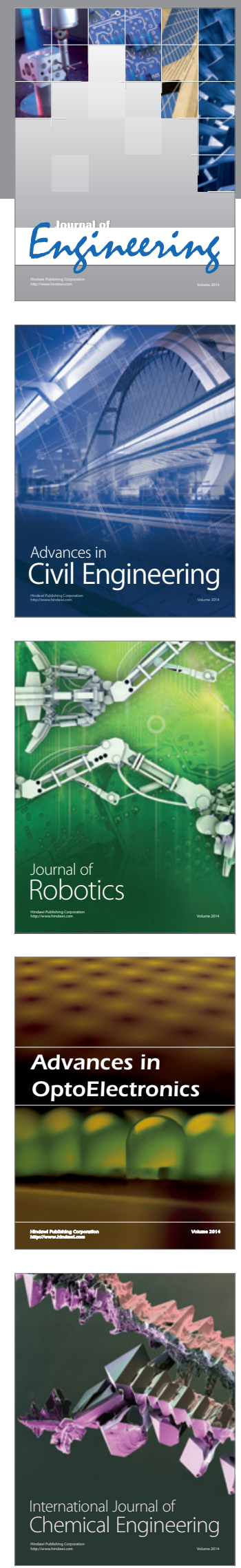

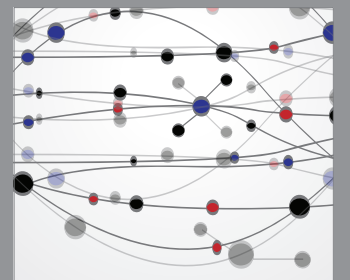

The Scientific World Journal
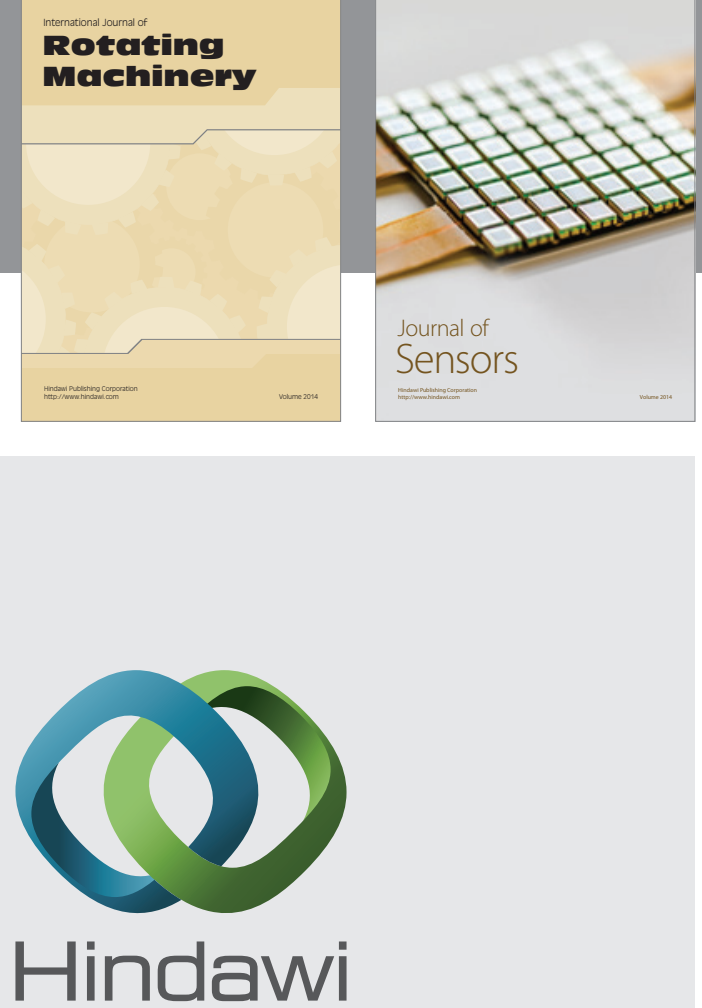

Submit your manuscripts at http://www.hindawi.com
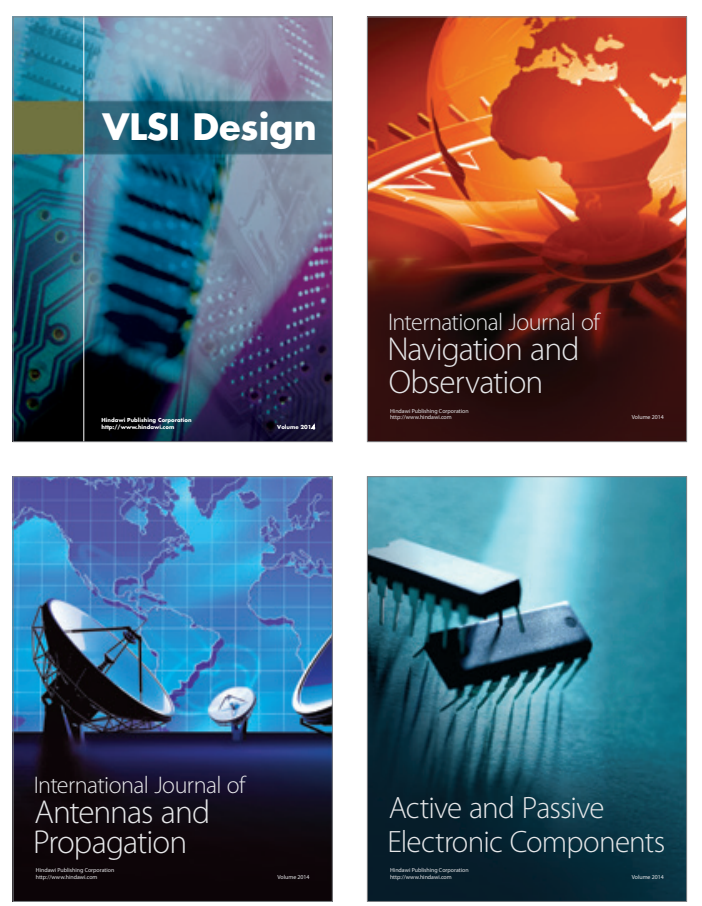
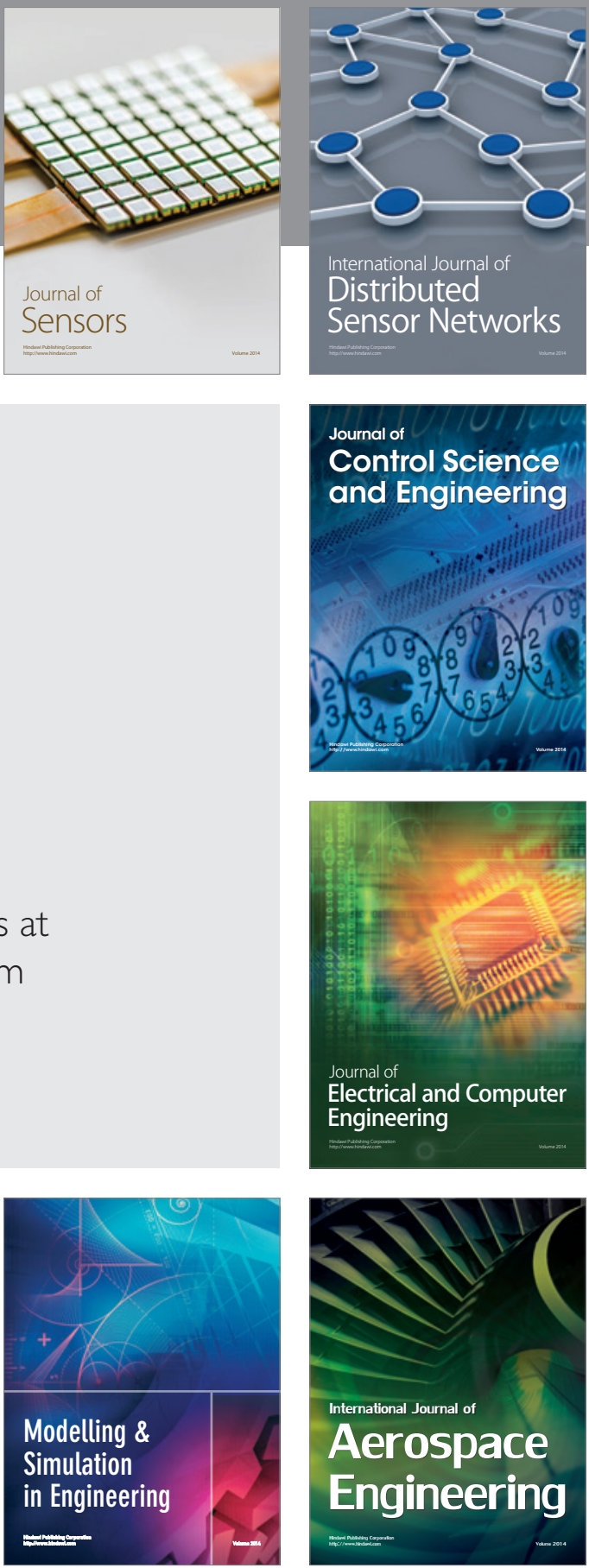

Journal of

Control Science

and Engineering
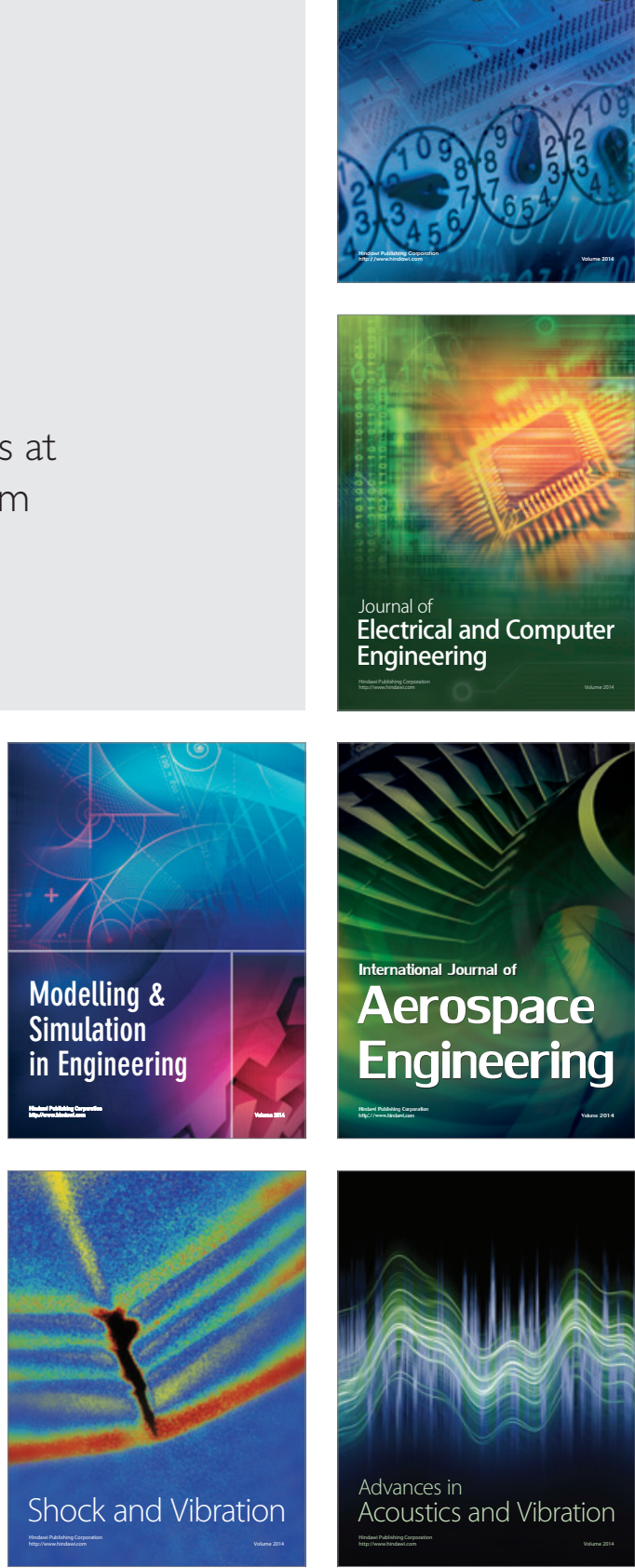